PROCEEDINGS OF THE 5TH WFOT MEETING; 2016 NOV 18-20; MUMBAI, INDIA

\title{
How to combine Ozone Therapies with other modalities for maximum efficacy
}

Suresh Shottam

India.

\section{ABSTRACT}

OOPEN ACCESS

\section{Citation}

Shottam S. How to combine Ozone Therapies with other modalities for maximum efficacy [abstract]. Proceedings of the 5Th WFOT Meeting; 2016 Nov 18-20; Mumbai, India. J Ozone Ther. 2018;2(2). doi: 10.7203/jo3t.2.2.2018.11157

\section{Academic Editor}

Jose Baeza-Noci, School of Medicine, Valencia University, SPAIN

\section{Editor}

World Federation of Ozone Therapy, Bolgna, ITALY

\section{Received}

December 9, 2017

\section{Accepted}

December 10, 2017

\section{Published}

March 4, 2018

\section{Intellectual Property}

Suresh Shottam. This is an open access article distributed under the terms of the Creative Commons Attribution License (CC BY 4.0), which permits unrestricted use, distribution, and reproduction in any medium, provided the original author and source are credited.
In order to use Bio-Oxidative Therapies effectively, a small shift in thinking is needed. One needs to shift from Disease Literacy to Healing Literacy

This shift in thinking leads to the inevitable conclusion that: Impaired Oxygen Signaling is the common denominator for all disease.

\section{Impaired Oxygen Signaling affects:}

- O2 driven energetics

- O2's detergent function

- O2's cellular repair function

- O2's renewal function

It is important to be aware of Oxygen's multiple functions in order to appreciate the importance of the role bio-oxidative therapies play in the reversal of disease conditions.

In fact, no treatment of chronic disease can be complete without addressing ALL Oxygen-related issues relevant to a particular patient.

What are these oxygen related issues that need to be addressed?

There are 4 distinct steps that lead to disease manifestation linked to Oxygen: · Dysfunctional Oxygen Metabolism - Acidosis · Oxidative Coagulation · Oxidized Lymph

Once the above conditions are understood, it becomes clear that combining bio-oxidative therapies with other modalities can improve the outcome of those modalities.

Examples of how to combine therapies to create effective protocols for improved clinical outcome will be discussed.

\section{IN SUMMARY}

A clear understanding of the Oxygen Model of Disease will enable the practitioner to customize and create innovative combinations for the individual patient.

\section{Author Information}

wellness.zone@gmail.com 